\title{
Morfologia do ovário da ema (Rhea americana) ${ }^{1}$
}

\author{
Rogério C. Parizzi ${ }^{2}$, Maria A. Miglino ${ }^{3}$, Marina O. Maia ${ }^{4}$, Joel A. Souza², José M. \\ Santos $^{5}$, Moacir F. Oliveira ${ }^{6}$ e Tatiana C. Santos ${ }^{3 *}$
}

\begin{abstract}
Parizzi R.C., Miglino M.A., Maia M.O., Souza J.A., Santos J.M., Oliveira M.F. \& Santos T.C. 2007. [Morphology of the ovary in rhea (Rhea americana).] Morfologia do ovário da ema (Rhea americana). Pesquisa Veterinária Brasileira 27(3):89-94. Departamento de Cirurgia, Faculdade de Medicina Veterinária e Zootecnia, USP, Av. Prof. Dr. Orlando Marques de Paiva 87, São Paulo, SP 05508-270.E-mail: tcsantos@usp.br

The ovarian morphology of the sexually mature rhea (Rhea Americana) is described. Ovaries from 24 adult rheas in their reproductive age were collected in the slaughterhouse. Follicular diameters $(n=18)$ were measured and samples $(n=6)$ were fixed in $10 \%$ formaldehyde with $0.1 \mathrm{M}$ phosphate buffer at $\mathrm{pH} 7.4$ for light microscopy. Results showed that the left ovary occupied the dorsal portion of the celomatic cavity in contact with the cranial portion of the left kidney and the suprarenal gland, being supported in the cavity through the mesovary. On the free surface of the ovary $72.4 \pm 17.09$ follicles in different phases of development and $30.4 \pm 3.65$ atretic follicles were observed. The follicles were linked to the ovarian surface by the follicular stalk and had a wide band surrounding its surface, the Stigma folliculare. Histologically, the ovary is constituted by a medulla, composed by connective tissue and vessels, and by a cortex with oocytes and follicles. The follicular wall is composed by the Theca externa and Theca interna, Stratum granulosum and the Zona radiata. The ovary surface is covered by a cubic epithelium, the germinal epithelium, on the connective tissue of the Tunica albuginea. The morphologic characteristics of the ovary of the rhea are due to the egg size in this species and generally similar to other birds.
\end{abstract}

INDEX TERMS: Ovary, follicle, morphology, avian anatomy, rhea, Rhea americana.

RESUMO.- A morfologia do ovário de emas adultas (Rhea americana) sexualmente maduras foi descrita neste trabalho. Os ovários de 24 fêmeas em fase reprodutiva foram colhidos em abatedouro, tomados dados métricos do diâmetro dos folículos $(\mathrm{n}=18)$ e colhidos fragmentos para microscopia de luz $(n=6)$ fixados em formol $10 \%$, PBS 0,1 M, pH 7,4 para microscopia de luz. Nas emas o ovário esquerdo está desenvolvido, ocupando a porção dorsal da cavidade celomática em contato com a porção cranial do rim

\footnotetext{
${ }^{1}$ Recebido em 18 de outubro de 2006.

Aceito para publicação em 14 de novembro de 2006.

2 Pós-Graduando em Anatomia dos Animais Domésticos, Faculdade de Medicina Veterinária e Zootecnia (FMVZ), Universidade de São Paulo (USP), Av. Prof. Dr. Orlando Marques de Paiva 87, São Paulo, SP 05508-270.

${ }^{3}$ Depto Cirurgia, FMVZ-USP. *Autor para correspondência: tcsantos@usp.br

${ }^{4}$ Graduando em Medicina Veterinária, FMVZ-USP.

${ }^{5}$ Universidade Anhembi Morumbi, Rua Dr. Almeida Lima 1134, São Paulo, SP 03164-000.

${ }^{6}$ Universidade Federal Rural do Semi-Árido (UFERSA), BR $110 \mathrm{Km} \mathrm{47,}$ Bairro Pres. Costa e Silva, Mossoró, RN 59625-900.
}

esquerdo e a glândula adrenal esquerda, sustentado na cavidade pelo mesovário. Na superfície livre do ovário foram observados em média 72,4 $\pm 17,09$ folículos em desenvolvimento e $30,4 \pm 3,65$ folículos atrésicos. Os folículos estão unidos à superfície ovariana pelo pedúnculo folicular e os em desenvolvimento apresentam uma cinta na superfície, o estigma folicular, rompida nos folículos atrésicos. Histologicamente, o ovário possui uma medula, com tecido conjuntivo frouxo e vasos sangüíneos e um córtex repleto de oócitos e folículos, cuja parede está constituída pelas tecas externa e interna, estrato granuloso e zona radiada. No córtex observam-se folículos primordiais, pré-vitelogênicos e vitelogênicos. A superfície do ovário está revestida por epitélio cúbico baixo, o epitélio germinativo, o qual está sobre o tecido conjuntivo da túnica albugínea. As características morfológicas do ovário da ema são resultado do tamanho do ovo produzido e em geral semelhante ao de outras espécies de aves.

TERMOS DE INDEXAÇÃO: Ovário, folículo, morfologia, anatomia das aves, ema, Rhea americana. 


\section{INTRODUÇÃO}

A ema pertence à ordem Rheiforme, família Rheidae e gênero Rhea, típica da fauna brasileira e sul-americana (Romer 1972), que quando adulta atinge $1,4-1,7 \mathrm{~m}$ de altura, com peso em torno de $35 \mathrm{~kg}$ (Olson 1983) e duas subespécies são conhecidas: Rhea americana americana e Rhea americana intermedia. A mais indicada para criação em cativeiro no Brasil é Rhea americana intermedia (Belton 1994) e a idade média para atingir a maturidade sexual é de 3 anos de idade, podendo alguns indivíduos iniciar seu papel reprodutivo aos 2 anos de idade (Dunning \& Belton 1993).

Os órgãos reprodutores da fêmea em aves são o ovário e o oviduto, tendo como função primária a produção viável de filhotes, através de ovos férteis pelos progenitores (Gilbert 1967). Estes órgãos se apresentam desenvolvidos apenas no lado esquerdo em aves adultas (King 1986). Os ovos da ema possuem tamanho aproximado de $132 \times 90 \mathrm{~mm}$, pesando em torno de $600 \mathrm{~g}$ (Hoyo et al. 1994) e cada fêmea produz de 12-30 ovos por estação de postura (Dunning \& Belton 1993).

No ovário tem início a produção do ovo e é formado por uma complexa estrutura responsável pela formação do óvulo, desde os folículos primordiais, seguindo suas fases de desenvolvimento formando os folículos pré-vitelogênicos (primários) e folículos vitelogênicos (secundários) maduros.

A criação de emas tem despertado interesse comercial em várias regiões do Brasil, com o crescente número de criadouros em atividade, visando à comercialização de seus produtos e subprodutos (ovos, filhotes, penas, carne, óleo e couro), tanto no mercado interno quanto para exportação. As descrições morfológicas na ema são escassas, principalmente em relação aos órgãos reprodutores e este trabalho tem o objetivo de fazer a descrição microscópica e macroscópica nesta espécie.

\section{MATERIAL E MÉTODOS}

Os ovários de emas foram processados para análise macroscópica e para microscopia de luz, sendo utilizadas 24 fêmeas de Rhea americana (Emas), das quais quatro filhotes de 2 semanas, que morreram em criadouros e 20 adultos, pesando de $25-40 \mathrm{~kg}$, e idade entre 12 e 36 meses, provenientes da Cooperativa Emas do Brasil Ltda (Inscrição 096/3042653, CNPJ 06923872-0001/08).

Este trabalho teve aprovação da Comissão de Bioética da Faculdade de Medicina Veterinária e Zootecnia da USP (Protocolo 707/ 2005) e do Instituto Brasileiro do Meio Ambiente e Recursos Naturais Renováveis (Proc. 02001.002532/05)

Os ovários foram identificados e tomados dados morfométricos como: número e diâmetro $(\mathrm{mm})$ dos folículos em desenvolvimento visíveis $(>1 \mathrm{~mm})$ do ovário, e classificados em pequenos $(1-20 \mathrm{~mm})$, médios (20-40 $\mathrm{mm})$ e grandes $(40-90 \mathrm{~mm})$ e folículos atrésicos $(>6 \mathrm{~mm})$ também classificados como pequenos (6-15mm), médios (16-25mm) e grandes (26-40mm).

Os dados do diâmetro dos folículos em desenvolvimento e atrésicos foram analisados pelo teste estatístico de Kolmogorov-Smirnov e os intervalos de classe foram comparados entre si e entre os tipos de folículos e os valores de $\mathrm{P}>0,05$ foram considerados significativos.

Fragmentos (jovens $\mathrm{n}=2$, adultas $\mathrm{n}=8$ ) representativos do ovário de suas diferentes regiões foram fixados em formol 10\%, tampão fosfato $0,1 \mathrm{M}, \mathrm{pH} 7,4$, desidratados em soluções crescentes de etanol (70-100\%), clarificados em xilol e parte emblocados em paraplast
(Sigma, Oxford, USA) e parte em glicol metacrilato (Historesina ${ }^{\circledR}$, Sigma, Oxford, USA). Cortes de $5 \mu \mathrm{m}$ (paraplast) ou $1 \mu \mathrm{m}$ (historesina), foram corados com Hematoxilina e Eosina (HE), Tricrômio de Masson e pela reação histoquímicia do Ácido Periódico de Schiff (PAS).

\section{RESULTADOS}

Nos filhotes (15 dias) de emas observam-se tanto o ovário e o oviduto esquerdos, quanto os direitos, no entanto, já nos primeiros dias de vida o ovário e o oviduto esquerdos apresentamse proporcionalmente maiores (Fig.1) e nas adultas estes estão desenvolvidos. Nas fêmeas adultas o ovário esquerdo ocupa a porção dorsal da região média da cavidade celomática, em contato com a porção cranial do rim esquerdo e com a glândula adrenal esquerda, sobrepondo-se à porção cranial do rim direito, ventralmente à extremidade caudal do pulmão. A face dorsal do ovário está inserida na parede dorsal da cavidade celomática por uma prega de peritônio, o mesovário.

Macroscopicamente observam-se, na superfície livre do ovário de emas adultas, folículos vitelogênicos em desenvolvimento em diferentes tamanhos, caracterizados por projeções arredondadas, sustentados pelo pedúnculo folicular, o qual está constituído por feixes de músculo liso, entremeado por tecido conjuntivo frouxo e vasos sanguíneos destinados ao folículo. A superficie livre de cada folículo apresenta uma cinta esbranquiçada, o estigma folicular, composto por tecido conjuntivo denso modelado e, o qual nos folículos maduros, considerados grandes, possui em média $5 \mathrm{~mm}$ de largura e, em alguns destes, formato irregular (Fig.2-4).

Em média foram observados $72,4 \pm 17,1$ folículos em desenvolvimento, classificados segundo seu diâmetro em pequenos, médios e grandes, cujo número de folículos observado por classe foi considerado estatisticamente diferente entre si $(P>0,05)$.

A superfície ovariana possui ainda folículos atrésicos (Calices ovarii) em diferentes estágios de regressão. Nos folículos atrésicos o estigma está rompido e permanece aberto medianamente, conferindo a forma de cálice ao folículo, cujas margens livres curvamse no sentido do interior do cálice. Apresenta histologicamente células intersticiais (luteínicas) que hipertrofiam e migram para o interior; ocorre proliferação de células da granulosa formando uma camada densa, característica dos folículos atrésicos, com grande quantidade de tecido conjuntivo, circundado por células foliculares (Fig.5 e 6). Em média observam-se 30.4 3 3.7 folículos atrésicos nos ovários das emas adultas. A análise estatística do número de folículos atrésicos demonstrou que houve diferenças significativas $(P>0,05)$ entre os intervalos de classe analisados (folículos pequenos, médios e grandes), bem como quando estas classes foram comparadas com as correspondentes de número de folículos em desenvolvimento (Fig.7, Quadro 1).

O ovário é constituído histologicamente por um córtex e uma medula. No córtex do ovário localizam-se folículos primordiais (diâmetro $<100 \mu \mathrm{m}$ ), pré-vitelogênicos (diâmetro 150$400 \mu \mathrm{m})$ e vitelogênicos $(>400 \mu \mathrm{m})$. A medula é constituída por tecido conjuntivo frouxo e vasos sanguíneos. Nos ovários adultos estas duas regiões misturam-se pela presença de grandes folículos.

A superfície do ovário está revestida por um epitélio cúbico baixo, o epitélio germinativo, o qual está sobre o tecido conjunti- 

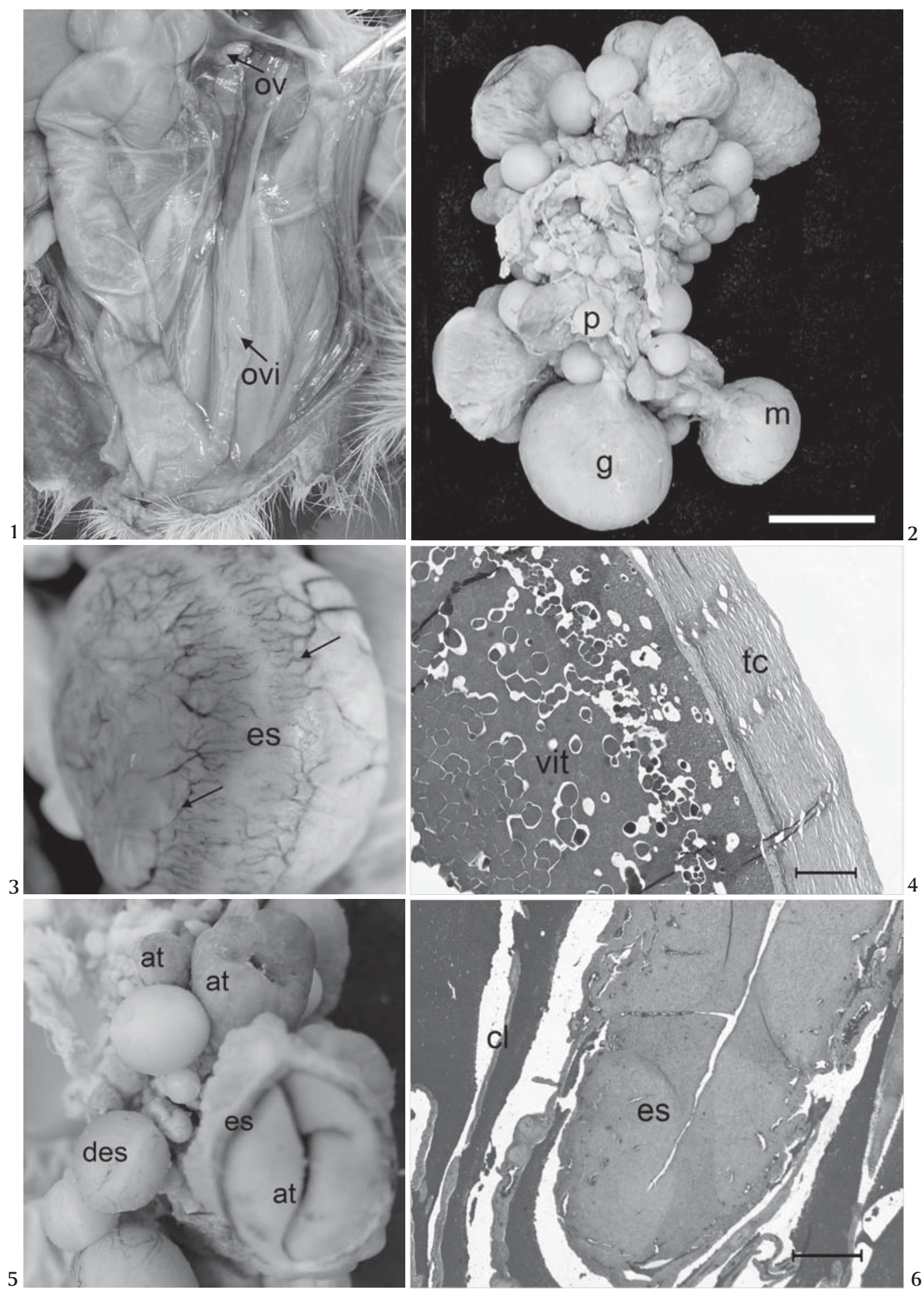

Fig.1. Ovário (ov) e oviduto (ovi) esquerdos em ema filhote (15 dias de idade).

Fig.3. Estigma folicular (es) na superfície livre do folículo, notar os vasos direcionados para o estigma (setas).

Fig.5. Folículos atrésicos (at) com o estigma (es) rompido e folículos em desenvolvimento (des).

Fig.2. Ovário de ema adulta com folículos pequenos (p), médios (m) e grandes $(\mathrm{g})$, sustentados pelo pedúnculo folicular (setas). Barra = $2 \mathrm{~cm}$.

Fig.4. Corte transversal do folículo onde se observam o tecido conjuntivo (tc) e o vitelo (vit). Paraplast, Tricrômio de Masson. Barra $=200 \mu \mathrm{m}$.

Fig.6. Corte transversal de folículo atrésico que apresenta tecido conjuntivo (tc) circundados por células foliculares (cf). Paraplast, Tricrômio de Masson. Barra $=200 \mu \mathrm{m}$. 
vo da túnica albugínea. A parede dos folículos está composta externamente pela teca externa, a maior porção da parede folicular, com fibras colágenas e fibroblastos (Fig.8 e 9). A teca interna, mais estreita, forma uma margem periférica de tecido, que envolve a camada cortical, internamente, constituída por tecido conjuntivo denso, fibras colágenas, fibroblastos e células vacuolares, que se distribuem em camadas paralelas pela circunferência do folículo

Quadro 1. Número de folículos em desenvolvimento e atrésicos na superfície ovariana de emas adultas $(n=10)$, classificados como pequenos, médios e grandes

\begin{tabular}{ccc}
\hline $\begin{array}{c}\text { Número de } \\
\text { folículos }\end{array}$ & $\begin{array}{c}\text { Folículos em } \\
\text { desenvolvimento }\end{array}$ & $\begin{array}{c}\text { Folículos } \\
\text { atrésicos }\end{array}$ \\
\hline Pequenos & $41,9 \pm 10,1^{\mathrm{Aa}}$ & $11,7 \pm 3,5^{\mathrm{Ab}}$ \\
Médios & $24,6 \pm 7,8^{\mathrm{Bb}}$ & $13,8 \pm 2,9^{\mathrm{Bc}}$ \\
Grandes & $5,9 \pm 1,2^{\mathrm{Cc}}$ & $4,9 \pm 1,2^{\mathrm{Ca}}$ \\
Total & $72,4 \pm 17,1$ & $30,4 \pm 3,7$ \\
\hline
\end{tabular}

Médias com letras diferentes diferem estatisticamente entre si $(P>0,05)$.

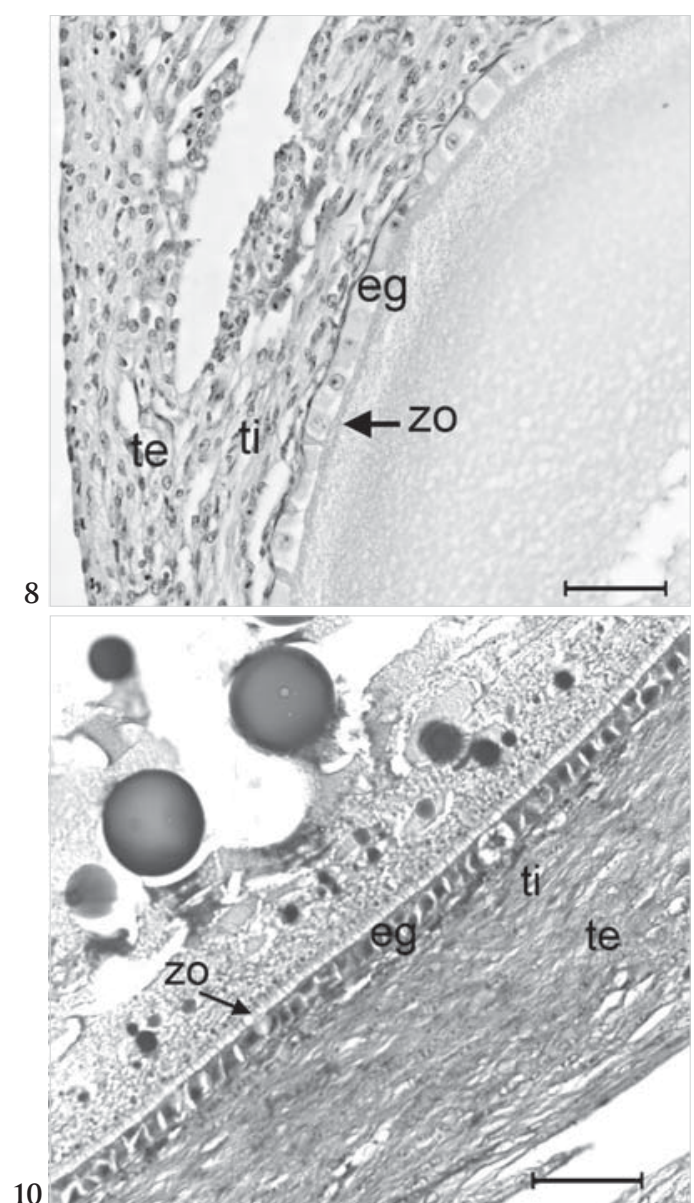

Fig.8. Folículo vitelogênico de ema adulta em que se observa a parede folicular composta pela teca externa (te), teca interna (ti), estrato granuloso (eg) e zona radiada (zo). Historesina, HE. Barra $=40 \mu \mathrm{m}$.

Fig.10. Fotomicrografia de folículo vitelogênico de ema adulta evidenciando a teca externa (te), a teca interna (ti), o estrato granuloso (eg) e a zona radiada (zo). Paraplast, Tricrômio de Masson. Barra $=50 \mu \mathrm{m}$.

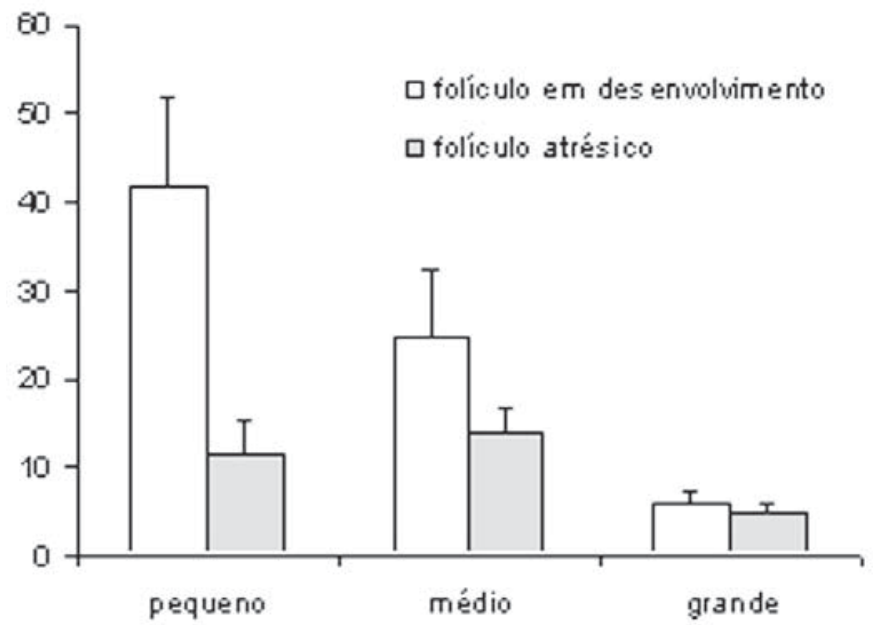

Fig.7. Número médio e desvio padrão dos folículos atrésicos e em desenvolvimento no ovário esquerdo de emas adultas em produção, classificados por tamanho.

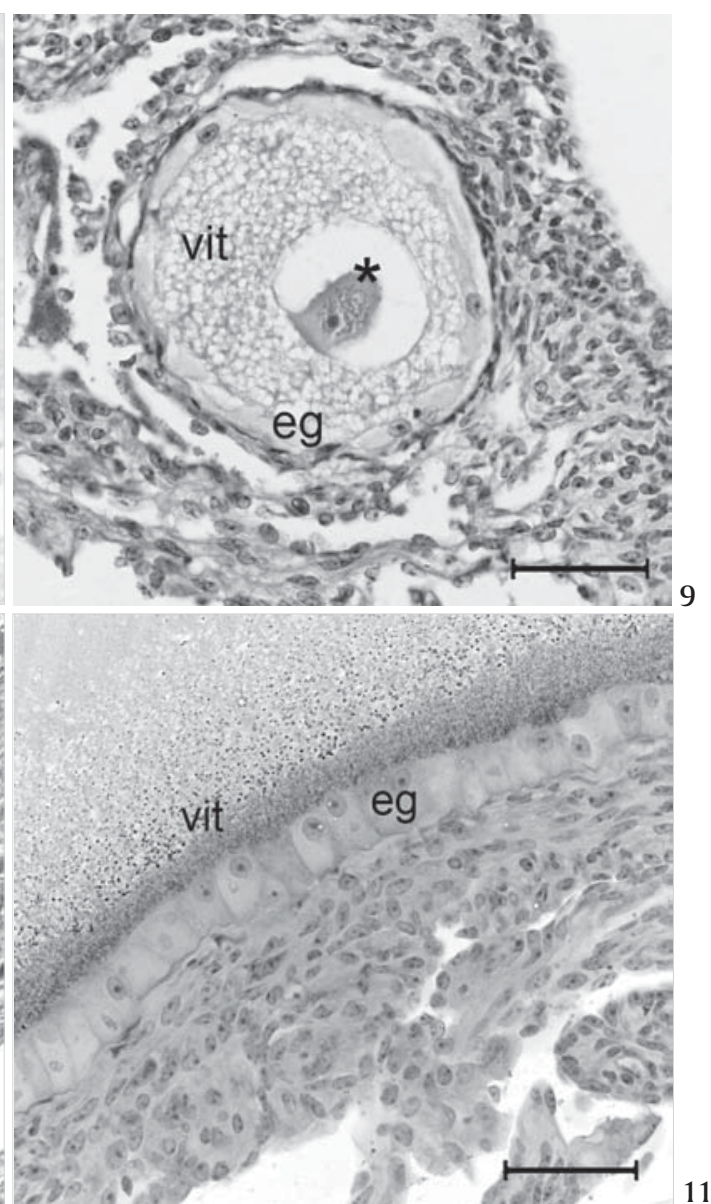

Fig.9. Folículo pré-vitelogênico em que se evidenciam as células cúbicas do estrato granuloso (eg), o núcleo do oócito (") e o vitelo (vit). Historesina, HE. Barra $=40 \mu \mathrm{m}$.

Fig.11. Detalhe da parede de folículo vitelogênico evidenciando os grânulos de secreção nas células do estrato granuloso (eg) e o vitelo (vit) PAS +. Historesina, PAS. Barra $=40 \mu \mathrm{m}$. 
(Fig.10). Internamente à teca interna está presente o epitélio folicular ou estrato granuloso. Em todos os tipos de folículos primordiais, pré-vitelogênicos e vitelogênicos as células do estrato granuloso são cúbicas e representam um epitélio simples, característico por núcleos grandes, esféricos com cromatina frouxa e citoplasma basófilo e grânulos PAS +.

Na análise histoquímica observa-se os componentes do vitelo PAS + . Sob o estrato granuloso localiza-se a zona radiada e a membrana perivitelínica, que está separada da superfície apical do epitélio folicular pela superfície externa do vitelo (Fig.11).

\section{DISCUSSÃO}

Nos animais adultos e púberes analisados, observamos o ovário esquerdo desenvolvido e o direito rudimentar, este último representado por uma pequena massa de tecido amorfo localizado na região dorsolateral da cloaca. No avestruz também não se observa macroscopicamente o ovário direito desenvolvido (Benzuidenhout 1986). Nos filhotes, com 15 dias de vida, notaram-se tanto o ovário e o oviduto esquerdo, quanto os direitos, no entanto, estes, no lado esquerdo, são proporcionalmente maiores. Em aves de um modo geral já na vida embrionária a gônada esquerda tem até cinco vezes o número de células germinativas que à direita e o ovário esquerdo muito cedo se torna maior que o direito (Amin \& Gilbert 1967).

A sintopia do ovário esquerdo na ema é comum a outras aves, ocupando a porção dorsal da região média da cavidade corporal ou celomática, em contato com a porção cranial do rim esquerdo e com a glândula adrenal esquerda, sobrepondo-se à porção cranial do rim direito, ventralmente à extremidade caudal do pulmão.

Madekurozwa \& Kimaro (2006) citam que folículos primordiais, pré-vitelogênicos e vitelogênicos são observados também na fêmea sexualmente imatura de avestruz. Os folículos prévitelogênicos correspondem aos folículos primários e os vitelogênicos aos secundários citados por outros autores. A possibilidade de existir um vasto número de folículos avaliáveis no ovário não evidencia que a ave chegou à maturidade reprodutiva, outro componente a ser avaliado é o número de folículos atrésicos (Hodges 1974). Nas galinhas em fase reprodutiva, em geral, a hierarquia consiste em 4-6 folículos em desenvolvimento, porém o número é variável de ave para ave (Yu \& Marquardt 1973). Cada folículo é geralmente formado em intervalos de 24 horas, mas não significa que sempre haverá esta diferença de tempo entre dois folículos em desenvolvimento (Gilbert 1971). Nos ovários de ema foram observados entre 4 e 8 folículos grandes (40-90mm) ou em adiantado estágio de desenvolvimento. Sobre este aspecto deve-se levar em consideração o intervalo maior da ema para postura de cada ovo. Na medula ovariana observamos tecido conjuntivo frouxo e vasos sanguíneos e, no córtex observam-se vários folículos em desenvolvimento, bem como folículos atrésicos. Nos ovários adultos das emas, como o citado em galinhas (Getty 1986, King 1986) a presença de grandes folículos dificulta a diferenciação destas áreas.

A atresia folicular ocorre durante todos os estágios de desenvolvimento folicular e dois tipos de atresia (Tipos 1 e 2) são identificados nos folículos vitelogênicos. Nos estágios avançados de atresia do Tipo 1 o folículo é invadido por uma massa hialinizada e em contraste, no Tipo 2 de atresia as células da granulosa e da teca interna diferenciadas penetram nas células intersticiais. Nos estágios avançados de atresia os folículos primordiais e prévitelogênicos são invadidos pelo estroma (Madekurozwa \& Kimaro 2006). Nas emas observamos folículos atrésicos em diferentes estágios de regressão, cujo diâmetro variou de 6 a 40mm. Uma semana após a ovulação no pato já não se observa a olho nu os remanescentes do folículo pós-ovulatório (Davis 1942). Em aves adultas sexualmente ativas normalmente encontram-se de 4-5 folículos pós-ovulatórios (Hodges 1974), nas emas o número de folículos atrésicos observados provavelmente é superior devido à diferença proporcional de tamanho dos folículos em desenvolvimento quando comparado a outras aves e pela massa de tecido que deverá ser reabsorvida nos folículos atrésicos.

A parede do folículo maduro da ema possui estrutura similar ao folículo de outras aves já descritas (Gilbert 1971, Bennet 1947). Histologicamente identificam-se a zona radiada, o extrato granuloso, a teca interna e a teca externa, e ainda uma túnica externa de tecido conjuntivo e o epitélio superficial. Estas e outras camadas identificadas somente pela microscopia eletrônica de transmissão, como o plasmalema do oócito, a lâmina perivitelínica, bem como a lâmina basal do folículo, são descritas em galinhas (Baumel et al. 1993, Bacha \& Bacha 2003). Gilbert (1967) comenta que o estrato granuloso nos folículos inicialmente está composto por várias camadas de células e com o crescimento do folículo esta camada torna-se simples, sugere-se também que pode estar composta por mais de um tipo celular. Folículos primordiais de avestruz geralmente ocorrem sozinhos, porém grupos de quatro ou cinco folículos são observados. A camada de células da granulosa nos folículos em desenvolvimento é colunar pseudo-estratificada e as camadas das tecas estão separadas por fibras de tecido conjuntivo (Madekurozwa \& Kimaro 2006). Nas emas, notamos que mesmo em folículos primários o estrato granuloso está composto claramente por apenas uma camada de células. Particularmente a teca externa compreende grande parte da parede folicular, composta pelas fibras musculares lisas conectadas às fibras colágenas e, internamente estão paralelas à circunferência interna do folículo, com numerosos fibroblastos entre elas. Esta estrutura similar na galinha poedeira confere a esta camada uma característica elástica (Bennet 1947).

O estigma folicular por sua vez, nos folículos ovarianos de ema é representado por uma faixa meridional de colágeno, de cerca de $5 \mathrm{~mm}$, e encontrado também em outras aves como a galinha (Guszal 1966). Na galinha o estigma é relativamente avascular, forma uma linha meridional branca e é constituído pela fusão do epitélio superficial e pela teca externa (King 1980). Apesar de não termos observados nenhum folículo em processo de ovulação, as características morfológicas destes na ema sugerem que nestes animais este processo ocorra semelhante ao que já está descrito para outras aves. A disposição das fibras colágenas na teca externa sugere que no momento da ovulação, a retração das paredes foliculares contribua para a passagem do oócito através da abertura produzida pelo rompimento do estigma. Este fenômeno é citado por Guzsal (1966) que descreve o tecido conjuntivo da teca e considera que estas possuam papel efetivo na ruptura do folículo na ovulação, pela característica elástica (Bennet 1947). 
Assim como ocorre nas galinhas, também nas emas cada folículo está suspenso por um pedúnculo ou talo folicular, constituído por feixes de músculo liso, entremeados por tecido conjuntivo frouxo (Gilbert 1967, King 1980). No interior do pedúnculo encontramse os músculos pedunculares e os músculos intramurais, que se estendem do talo para formar uma camada muscular entre a túnica superficial e a teca externa (King 1986). Nas emas o tamanho dos folículos resulta em pedúnculos consistentes.

Concluindo, o ovário da ema adulta compartilha em termos gerais a morfologia descrita para aves, com ovário esquerdo desenvolvido em forma de cacho e repleto de folículos em desenvolvimento e atrésicos, cujo tamanho é particular para ratitas devido ao grande ovo produzido. A estrutura dos folículos também é similar ao de outras aves e os dados descritos podem colaborar para a morfologia comparada bem como servir de suporte para futuras pesquisas na espécie.

Agradecimentos.- À Cooperativa Emas do Brasil e à CAPES pelo suporte financeiro.

\section{REFERÊNCIAS}

Amin S.O. \& Gilbert A.B. 1967. Cellular changes in the anterior pituitary of the domestic fowl during growth, sexual maturity and laying. Brit. Poult. Sci. 11:451-458.

Bacha Jr W.J. \& Bacha L.M. 2003. Atlas Colorido de Histologia Veterinária. $2^{2}$ ed. Editora Roca, São Paulo, p.358-389.

Baumel J.L., King A.S., Breazile J.E., Evans H.S. \& Berge J.C.V. 1993. Handbook of Avian Anatomy. $2^{\text {nd }}$ ed. Nuttall Ornithology Club, Cambridge, p.370397.

Belton W. 1994. Aves do Rio Grande do Sul: distribuição e biologia. Editora Unisinos, Porto Alegre, p.43-44.

Bennet C.H. 1947. Relation between size age of the gonads in the fowl from hatching date to sexual mature. Poult. Sci. 26:99-104.
Davis D.E. 1942. The regression of the avian post-ovulatory follicle. Reprod. Domest. Duck 42:129-131.

Dunnig J. \& Belton W. 1993. Aves Silvestres do Rio Grande do Sul. 3ª ed. Fundação Zoobotânica do Rio Grande do Sul, Porto Alegre, p.22-23.

Getty R. 1986. Sisson and Grossman's Anatomia dos Animais Domésticos. Vol.2. 5 $5^{\mathrm{a}}$ ed. Guanabara Koogan, Rio de Janeiro, p.1813-1835.

Gilbert A.B. 1967. Formation of the egg in the domestic chicken, p.111180. In: Maclaren A. (ed.), Advances in Reproductive Physiology. Vol.2. Logos Press, London.

Gilbert A.B. 1971. The ovary, p.1163-1208. In: Bell D.J. \& Freeman B.M. (ed.), Physiology and Biochemistry of the Domestic Fowl. Vol.3. Academic Press, London.

Guzsal E. 1966. Histological studies on the mature and post-ovulation ovarian follicle of the fowl. Acta Vet. Acad. Sci. Hung. 16:37-44.

Hodges R.D. 1974. Histology of the Fowl. Academic Press, New York, p.344-349.

Hoyo J.D., Elliott A. \& Sargatal J. 1994. Handbook of the Fowl. Vol.1. Lynx Edicion, Barcelona, p.76-91.

King A.S. 1986. Aparelho urogenital das aves, p.1813-1828. In: Getty R. (ed.), Sisson and Grossman's Anatomia dos Animais Domésticos. Vol.2. Interamericana, Rio de Janeiro.

King A.S. 1980. Systema urogenitale, p.370-397. In: Baumel J.J., King A.S., Lucas A.M., Breazile J. \& Evans H.E. (ed.), Nomina Anatômica Avium. Academic Press, New York.

Madekurozwa M.C. \& Kimaro W.H. 2006. A morphological and immunohistochemical study of healthy and atretic follicles in the ovary of the sexually immature ostrich (Struthio camelus). Anat. Histol. Embryol. 35:253-258.

Olson S.L. 1983. Lessons from a flightless Ibis. Nat. History 92:40-41.

Romer A.S. 1972. Anatomia Comparada dos Invertebrados. $3^{\mathrm{a}}$ ed. Editorial Panamericana, México.

Yu J.Y.L. \& Marquardt R.R. 1973. Hyperplasia and hypertrophy of the chicken (Gallus domesticus) oviduct during a reproductive cycle. Poult. Sci. 53:1096-1105. 